Original Research Paper

\title{
Chemical Constituents, Antibacterial and Coagulation Activity of the Essential Oil from the Stem of Artemisia argyle H. Lév.
}

\author{
Jiale Shan and *Hongli Zhou \\ School of Chemistry and Pharmaceutical Engineering, Jilin Institute of Chemical Technology, Jilin 132022, PR China
}

Article history

Received: 29-03-2021

Revised: 13-05-2021

Accepted: 22-05-2021

Corresponding Author:

Hongli Zhou

School of Chemistry and Pharmaceutical Engineering,

Jilin Institute of Chemical

Technology, Jilin 132022, PR

China

E-mail: zhouhongli@jlict.edu.cn

\begin{abstract}
Artemisia argyle H. Lév. (A. argyle) is a plant of historical importance known as the "mother of herbs" in the Middle Ages. As the leaves of $A$. argyle have been studied more, but the stems has not been reported. This paper explores the chemical constituents, antibacterial and coagulation activities of the Essential Oil from the Stems of A. argyle (EOSAA) for better exploitation and utilization of resources. EOSAA was extracted by hydrodistillation and its chemical constituents were determined by GC-MS. Escherichia coli, Staphylococcus aureus and Bacillus pumilus were used as test microbial strains to evaluate the antimicrobial potential of EOSAA. Three indicators of Activated Partial Thromboplastin Time (APTT), Prothrombin Time (PT) and Thrombin Time (TT) were used to evaluate the coagulation activity. The extraction rate was $0.20 \%$ and 36 compounds were identified, accounting for $93.75 \%$ of the total content. Among the identified compounds, $41.72 \%$ belong to oxiterpenes, $21.31 \%$ belong to sesquiterpenes and terpenoids are extremely abundant. The main constituents were as follows: 3Biphenylmethanol (16.01\%), 2,6-Dimethyl-8-(tetrahydropyran-2yloxy)-octa-2,6-dien-1-ol (9.22\%), Germacrene D (7.22\%), $\alpha$-Bisabolol (5.85\%), L(-)-Borneol (5.75\%), Eucalyptol (5.71\%) and so on. EOSAA exhibited certain inhibitory effects against Escherichia coli, Staphylococcus aureus and Bacillus pumilus, the minimum inhibitory concentrations were 40, 42 and $48 \mathrm{mg} / \mathrm{mL}$, respectively. Compared with Yunnan Baiyao, APTT, PT and TT time of high concentration (60 $\mathrm{mg} / \mathrm{mL}$ ) EOSAA were shortened by $28.83,42.86$ and $68.99 \%$, respectively. The experimental results show that EOSAA is a natural coagulant with antibacterial effect and has a broad application prospect.
\end{abstract}

Keywords: Artemisia argyi H. Lév, Essential Oil, Chemical Constituents, Antibacterial Activity, Coagulation Activity

\section{Introduction}

Artemisia argyle H. Lév. (A. argyle) is a plant of the genus Artemisia in the compositae family which appears perennial herbs or slightly subshrub forms with strong fragrance. It widely distributes around the world (Zhang et al., 2013). A. argyi has been received considerable attention due to its abundant bioactive substances. The leaves of $A$. argyle smoke have obvious antibacterial effect on the affected area, reducing the number of bacterial colonies in the air and completely inhibiting the growth of pyogenic bacteria (Zhang et al.,
2014). The leaves of A. argyle are one of the common gynecological drugs, which were recorded as "hemostatic drugs" in medical records of past dynasties (Tan et al., 1992; Zheng et al., 2004), regulating the meridians and protecting the fetus, etc. (Adams et al., 2012). Pharmacological studies show that A. argyle has the effect of anti-fibrinolysis hemostasis by reducing capillary permeability (Yu et al., 2012). A. argyle is a traditional Chinese medicine and the whole grass can be used as medicine (Li et al., 2008).

The leaves of $A$. argyle contain essential oil, flavonoids, glycosides, terpenoids and other active 
compounds, among which the essential oil is the most important chemical component. For example, the Essential Oil of $A$. argyi Leaves (EOLAA) showed antihistaminic effects and antifungal activity (Huang et al., 2012). Moreover, EOLAA had strong antibacterial effects against Staphylococcus aureus, Escherichia coli and Salmonella enteritidis (Smith-Palmer et al., 2001). The chemical constituents of the EOLAA are extensive and thorough, mainly including eucalyptol, thujone, alcanfor and borneol (Xiang et al., 2018; Junjie et al., 2016). According to traditional knowledge and medical records, the roots, stems, leaves, buds and flowers of fresh or dried plants all contain some active ingredients that can cure some diseases (Lae et al., 2019). For $A$. argyle, in addition to the leaves, the stems are also rich in chemical constituents. In the current study, usually only the leaves are fully utilized, while the stems are discarded as waste, which not only causes environmental pollution but also wastes resources.

At present, there are numerous reports about the leaves of $A$. argyle, but few on stems. Herewith, the chemical constituents and its antibacterial and coagulation activity of Essential Oil from the Stems of A. argyle (EOSAA) obtained by hydrodistillation were done in this study, which has a broad application prospect as a kind of natural coagulant with antibacterial effect.

\section{Materials and Methods}

\section{Materials}

The samples were collected in June 2019 in Longtan District, Jilin City, Jilin Province. The voucher specimen (20190612) was preserved in the herbarium of Jilin Engineering Research Center for Agricultural Resources and Comprehensive Utilization, Jilin Institute of Chemical Technology, Jilin, China. All chemicals and reagents were of analytical grade and microbial strains were purchased from Beijing Zhongke Zesheng Biotechnology Co., Ltd. (Beijing, China). Assay kits used for the determination of Prothrombin Time (PT), Thrombin Time (TT) and Activated Partial Thromboplastin Time (APTT) content were provided by SINNOWA Medical Science and Technology Co., Ltd (Nanjing, Jiangsu, China). The fresh plasma kits were purchased from Dade Behring Marburg Gmbh (Marburg, Hesse, Germany).

\section{Methods}

\section{Extraction of Essential Oil}

Fresh stems of $A$. argyle $(60 \mathrm{~g})$ were placed into a $1000 \mathrm{~mL}$ two-necked flask equipped with $600 \mathrm{~mL}$ of distilled water and connected with a Clevenger-type device, then heated together for $3 \mathrm{~h}$. The essential oil was collected, dried with anhydrous $\mathrm{Na}_{2} \mathrm{SO}_{4}$ and hermetically stored at $0^{\circ} \mathrm{C}$ for $\mathrm{GC}-\mathrm{MS}$ analysis (Sparkman, 2005).

\section{Component Analysis}

\section{GC-MS Analysis}

The chemical composition of EOSAA was analyzed by GCMS-QP2010 instrument (Shimadzu, Kyoto, Japan) and the column was Rxi-5sil columnn $(30 \mathrm{~m}, 0.25 \mathrm{~mm}$, film thickness $0.25 \mu \mathrm{m}$ ). The carrier gas was nitrogen and flow rate was $1 \mathrm{ml} / \mathrm{min}$. The collision energy for Mass Spectrometry (MS) detection was $70 \mathrm{eV}$ and data were recorded within 40-450 amu. The vaporizer temperature and ion-source temperature were respectively adjusted to 280 and $230^{\circ} \mathrm{C}$. Each chemical composition was identified by comparing the retention index obtained from a database (NIST05) with the retention indexes calculated on the basis of n-alkanes $\left(\mathrm{C}_{9}-\mathrm{C}_{46}\right)$ (Rehman et al., 2021; Chzhu et al., 2020).

An essential oil sample dissolved in diethyl ether $(60 \mathrm{mg} / \mathrm{ml})$ was injected automatically into a vaporizer at $250^{\circ} \mathrm{C}$ with a split ratio of $1: 30$, the conditions of the column temperature were as follows: Starting at $60^{\circ} \mathrm{C}$ and maintaining it for $6 \mathrm{~min}$; then increasing 60 to $300^{\circ} \mathrm{C}$ at $3^{\circ} \mathrm{C} / \mathrm{min}$; finally keeping $300^{\circ} \mathrm{C}$ for $10 \mathrm{~min}$ (Padalia et al., 2016).

\section{Antibacterial Activity}

Escherichia coli ATCC 33456, Staphylococcus aureus ATCC 49775 and Bacillus pumilus ATCC 700814 were used as test microbial strains to evaluate the antimicrobial potential of EOSAA. Using $50 \%$ Dimethyl Sulfoxide (DMSO) as solvent, then the EOSAA solution was successively diluted to $100 \sim 10$ $\mathrm{mg} / \mathrm{ml}$ by 2 folds dilution method. Adding 50 microliters solution to 96 -well plate and $150 \mu \mathrm{L}$ microorganism liquid which was prepared by fresh nutrient medium containing $10^{7} \sim 10^{8} \mathrm{CFU} / \mathrm{ml}$ microbial strains were added into each hole, then it was placed in an incubator at $37^{\circ} \mathrm{C}$ for $24 \mathrm{~h}$, after that the absorbance was measured at 600 nm. Chloramphenicol solution $(100 \sim 1 \mathrm{mg} / \mathrm{ml})$ was used as the positive control and 50\% DMSO as the negative control (Zheng et al., 2019; Toledo et al., 2020).

\section{Coagulation Activity}

Taking $0.50 \%$ Yunnan Baiyao (a well-known hemostatic on the market, positive control) and $0.90 \%$ $\mathrm{NaCl}$ (blank control) as reference, the coagulation test was carried out using CL-2000BV coagulometer (Jiangsu Xenova medical Technology Co., Ltd, China) to determine the coagulation activity of EOSAA. Three indicators of Activated Partial Thromboplastin Time (APTT), Thrombin Time (TT) and Prothrombin Time (PT) were used to evaluate the coagulation activity. 


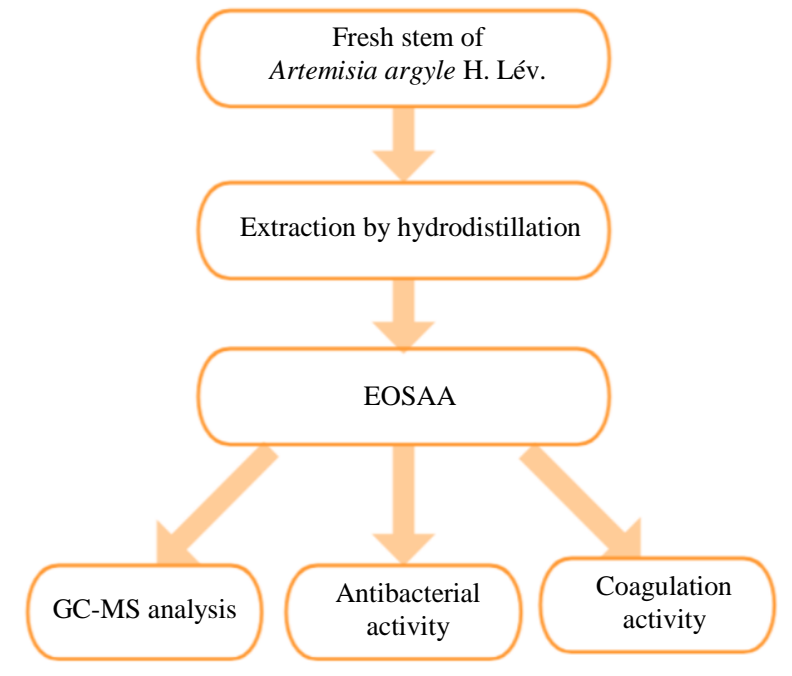

Fig. 1: The flow chart of the experiment methods

Plasma pretreatment: $0.109 \mathrm{~mol} / \mathrm{L}$ sodium citrate was accurately mixed with fresh plasma kits (Dade Behring Marburg Gmbh) at a volume ratio of 1:9 and centrifuged at $3000 \mathrm{r} / \mathrm{min}$ for $20 \mathrm{~min}$. The supernatant of platelet-poor plasma was collected, sealed with plastic tubes and took the refrigerated preservation. Before the experiment, the plasma preheating was carried out at $37^{\circ} \mathrm{C}$. Note that all experiments in this process were carried out at $37^{\circ} \mathrm{C}$ and should be completed within $2 \mathrm{~h}$ (Dore et al., 2013).

\section{APTT Assay}

$20 \mu \mathrm{L}$ of five different concentrations of EOSAA (20, $30,40,50$ and $60 \mathrm{mg} / \mathrm{mL}$ ) and $80 \mu \mathrm{L}$ of plasma were incubated for $1 \mathrm{~min}$, then added $100 \mu \mathrm{L}$ APTT reagent and continue to incubate for $1 \mathrm{~min}$, at last $25 \mathrm{mmol} / \mathrm{L} \mathrm{CaCl}$ $(100 \mu \mathrm{L})$ was added (Martinichen-Herrero et al., 2005).

\section{PT Assay}

$20 \mu \mathrm{L}$ of five different concentrations of EOSAA $(20,30,40,50$ and $60 \mathrm{mg} / \mathrm{mL})$ and same plasma were incubated for $30 \mathrm{~s}$, then $200 \mu \mathrm{L}$ of PT reagent was added to the above mixture (Sun et al., 2018).

\section{TT Assay}

$20 \mu \mathrm{L}$ of five different concentrations of EOSAA (20, $30,40,50$ and $60 \mathrm{mg} / \mathrm{mL}$ ) were incubated with same plasma for $30 \mathrm{~s}$, then $0.1 \mathrm{~mL}$ of preheated TT reagent was added to the above mixture (Wang et al., 2013).

In a word, the flow chart of the experiment methods is shown in Fig. 1.

\section{Results and Discussion}

\section{GC-MS Analysis}

The EOSAA was extracted by hydrodistillation and the blackish green oil was obtained with the extraction rate of $0.20 \%$. 36 compounds were identified by gas chromatography-mass spectrometer (GC-MS) with total contents of $93.75 \%$ (Table 1). The results were as follows: 3-Biphenylmethanol (16.01\%), 2,6-Dimethyl-8(tetrahydropyran-2-yloxy)-octa-2,6-dien-1-ol (9.22\%), Germacrene D (7.22\%), $\alpha$-Bisabolol (5.85\%), L(-)-Borneol $(5.75 \%)$, Eucalyptol $(5.71 \%),(\mathrm{R})$-camphor $(2.05 \%),(+)-$ 3 -Thujone $(1.82 \%)$ and so on. In the identified compounds, where $41.72 \%$ of the compounds belonged to oxyterpenes terpenes, followed by sesquiterpenes with content of $21.31 \%$, this indicates that terpenoids are extremely abundant.

The EOLAA was extracted by hydrodistillation and the extraction rate was $0.50 \%$ (Guan et al., 2019). The main chemical components of the EOLAA were identified by GC-MS as monoterpenes and their derivatives, sesquiterpenes and their derivatives, ketones (aldehydes) and so on (Pan et al., 2012), the main active compounds are eucalyptol (14.67\%), camphor $(6.87 \%)$, borneol $(6.482 \%), \alpha$-Thujone $(7.989 \%)$, caryophyllene oxide and so on (Dhanapal et al., 2016; Guan et al., 2019). Eucalyptol (5.71\%), camphor (2.05\%) and borneol $(5.75 \%)$ were found in the EOSAA, but the content was lower than that of the EOLAA. Because the constituents of the essential oil of A. Argyi is different due to the different parts, the content is also different, but both the main parts are generally eucalyptol, camphor, borneol, platycladone, caryophyllene, oxidative caryophyllene and so on (Hu et al., 2020).

\section{Antibacterial Activity}

The Minimum Inhibitory Concentration (MIC) values of EOSAA against Escherichia coli, Staphylococcus aureus and Bacillus pumilus were shown in Table 2. EOSAA has a certain inhibitory effect on Escherichia coli, Staphylococcus aureus and Bacillus pumilus, which may be related to its a large amount of terpenoids containing oxygen, such as, $\alpha$-Bisabolol, L(-)-Borneol, Eucalyptol and so on (Popović et al., 2010; de Morais et al., 2016). Borneol is a valuable medicinal ingredient, advanced flavor and chemical used in food and folk medicine in China and India for its anti-inflammatory and neuroprotective properties (Asadollahi et al., 2019). Eucalyptol has antibacterial, anti-inflammatory and antioxidation effects (Jiang et al., 2019). So antibacterial activity of EOSAA may be related to terpenoids, terpenoids have antimicrobial and bactericidal activities, which can destroy the permeability of cell membranes (Yang et al., 2019), lead to the leakage of nucleic acid and other macromolecular substances and interfere with the synthesis and accumulation of cell bacterial proteins. In addition, terpene interactions can induce changes in cellular respiration, leading to the subsequent decoupling of microbial oxidative phosphorylation (Zengin and Baysal, 2014), which has synergistic inhibitory effects on drug-resistant bacteria. (Zacchino et al., 2017). 
Table 1: Chemical constituents of the EOSAA by hydrodistillation and analyzed by GC-MS

\begin{tabular}{|c|c|c|c|c|c|}
\hline NO. & Compounds & $\mathrm{RI}^{\mathrm{a}}$ & $\mathrm{RI}^{\mathrm{b}}$ & Molecular formula & $\%$ \\
\hline 1 & $\alpha$-Phellandrene & 969 & 969 & $\mathrm{C}_{10} \mathrm{H}_{16}$ & 0.84 \\
\hline 2 & Eucalyptol & 1012 & 1031 & $\mathrm{C}_{10} \mathrm{H}_{18} \mathrm{O}$ & 5.71 \\
\hline 3 & (+)-3-Thujone & 1062 & 1109 & $\mathrm{C}_{10} \mathrm{H}_{16} \mathrm{O}$ & 1.82 \\
\hline 4 & (R)-camphor & 1121 & 1156 & $\mathrm{C}_{10} \mathrm{H}_{16} \mathrm{O}$ & 2.05 \\
\hline 5 & L(-)-Borneol & 1138 & 1186 & $\mathrm{C}_{10} \mathrm{H}_{18} \mathrm{O}$ & 5.75 \\
\hline 6 & cis- $\beta$-Terpineol & 1158 & 1201 & $\mathrm{C}_{10} \mathrm{H}_{18} \mathrm{O}$ & 1.15 \\
\hline 7 & $\gamma$-Terpineol & 1191 & 1221 & $\mathrm{C}_{10} \mathrm{H}_{18} \mathrm{O}$ & 2.38 \\
\hline 8 & Nerol & 1228 & 1231 & $\mathrm{C}_{10} \mathrm{H}_{18} \mathrm{O}$ & 1.26 \\
\hline 9 & L-alloaromadendrene & 1386 & 1422 & $\mathrm{C}_{15} \mathrm{H}_{24}$ & 3.81 \\
\hline 10 & $\beta$-sesquiphellandrene & 1446 & 1457 & $\mathrm{C}_{15} \mathrm{H}_{24}$ & 4.88 \\
\hline 11 & 1,4,6-Trimethyl-5,8-dihydronaphthalene & 1465 & 1495 & $\mathrm{C}_{13} \mathrm{H}_{16}$ & 0.85 \\
\hline 12 & $\beta$-selinene & 1469 & 1505 & $\mathrm{C}_{15} \mathrm{H}_{24}$ & 0.77 \\
\hline 13 & (-)-Isocaryophyllene & 1494 & 1511 & $\mathrm{C}_{15} \mathrm{H}_{24}$ & 3 \\
\hline 14 & Germacrene D & 1515 & 1512 & $\mathrm{C}_{15} \mathrm{H}_{24}$ & 7.22 \\
\hline 15 & $\alpha$-Bisabolene & 1518 & 1586 & $\mathrm{C}_{15} \mathrm{H}_{24}$ & 0.83 \\
\hline 16 & Viridiflorol & 1530 & 1589 & $\mathrm{C}_{15} \mathrm{H}_{26} \mathrm{O}$ & 0.8 \\
\hline 17 & Linalyl valerate & 1570 & 1593 & $\mathrm{C}_{15} \mathrm{H}_{26} \mathrm{O}_{2}$ & 1.35 \\
\hline 18 & $\beta$-Humulene & 1574 & 1614 & $\mathrm{C}_{15} \mathrm{H}_{24}$ & 0.8 \\
\hline 19 & $\alpha$-Cadinol & 1580 & 1616 & $\mathrm{C}_{15} \mathrm{H}_{26} \mathrm{O}$ & 1.44 \\
\hline 20 & Guaiol & 1614 & 1647 & $\mathrm{C}_{15} \mathrm{H}_{26} \mathrm{O}$ & 1.46 \\
\hline 21 & $\alpha$-Bisabolol & 1625 & 1660 & $\mathrm{C}_{15} \mathrm{H}_{26} \mathrm{O}$ & 5.85 \\
\hline 22 & Octahydroanthracene & 1652 & 1686 & $\mathrm{C}_{14} \mathrm{H}_{18}$ & 1.13 \\
\hline 23 & 1,2,3,4-tetrahydroanthracene & 1717 & 1697 & $\mathrm{C}_{14} \mathrm{H}_{14}$ & 1.06 \\
\hline 24 & 3-Biphenylmethanol & 1723 & 1770 & $\mathrm{C}_{13} \mathrm{H}_{12} \mathrm{O}$ & 16.01 \\
\hline 25 & 2,6-Dimethyl-8-(tetrahydropyran-2-yloxy)-octa-2,6-dien-1-ol & 1953 & 2024 & $\mathrm{C}_{15} \mathrm{H}_{26} \mathrm{O}_{3}$ & 9.22 \\
\hline 26 & Mono-2-ethylhexyl phthalate & 2162 & 2167 & $\mathrm{C}_{16} \mathrm{H}_{22} \mathrm{O}_{4}$ & 1.25 \\
\hline 27 & Thunbergol & 2211 & 2281 & $\mathrm{C}_{20} \mathrm{H}_{34} \mathrm{O}$ & 1.22 \\
\hline 28 & Pentacosane & 2506 & 2568 & $\mathrm{C}_{25} \mathrm{H}_{52}$ & 0.77 \\
\hline 29 & Hexanedioic acid, dioctyl ester & 2543 & 2571 & $\mathrm{C}_{22} \mathrm{H}_{42} \mathrm{O}_{4}$ & 1.13 \\
\hline 30 & Triacontane & 3003 & 3111 & $\mathrm{C}_{30} \mathrm{H}_{62}$ & 1.46 \\
\hline 31 & Pentatriacontane & 3500 & 3503 & $\mathrm{C}_{35} \mathrm{H}_{72}$ & 0.96 \\
\hline 32 & 17-Pentatriacontene & 3508 & 3570 & $\mathrm{C}_{35} \mathrm{H}_{70}$ & 1.3 \\
\hline 33 & Tetracontane & 3997 & 4003 & $\mathrm{C}_{40} \mathrm{H}_{82}$ & 0.79 \\
\hline 34 & 2,3-bis $[(3,7,11,15$-tetramethylhexadecyl)oxy]propan-1-ol & 4113 & 4183 & $\mathrm{C}_{43} \mathrm{H}_{88} \mathrm{O}_{3}$ & 1.75 \\
\hline \multirow[t]{5}{*}{35} & Tetratetracontane & 4395 & 4247 & $\mathrm{C}_{44} \mathrm{H}_{90}$ & 1.68 \\
\hline & Oxygen terpene & & & & 43.4 \\
\hline & Sesquiterpenes & & & & 25.65 \\
\hline & lignans & & & & 16.01 \\
\hline & Others & & & & 10.37 \\
\hline
\end{tabular}

$\mathrm{RI}^{\mathrm{a}}$ Retention indices relative to $\mathrm{C}_{8}-\mathrm{C}_{46} \mathrm{n}$-alkanes on a HP-5MS column

$\mathrm{RI}^{\mathrm{b}}$ is based and calculated on retention time relative to $\mathrm{C}_{9}-\mathrm{C}_{46}$

Table 2: MIC values of EOSAA

\begin{tabular}{llll}
\hline & E. coli & S. aureus & B. pumilus \\
\hline EOSAA $(\mathrm{mg} / \mathrm{mL})$ & 40 & 42 & 48 \\
Chloramphenicol $(\mathrm{mg} / \mathrm{mL})$ & $<0.8$ & $<0.8$ & $<0.8$ \\
\hline
\end{tabular}

Table 3: The coagulation activity of EOSAA

\begin{tabular}{lllll}
\hline Samples & Concentration $(\mathrm{mg} / \mathrm{mL})$ & APTT $(\mathrm{s})$ & PT $(\mathrm{s})$ & TT(s) \\
\hline EOSAA & 60 & $23.7 \pm 2.9^{* * * \#}$ & $3.2 \pm 0.7^{* * * * *}$ & $4.0 \pm 0.4^{* * * * \#}$ \\
& 50 & $25.6 \pm 2.4^{* * * * \#}$ & $8.2 \pm 1.4^{* * \#}$ & $4.9 \pm 0.8^{* * * * *}$ \\
& 40 & $41.0 \pm 1.9^{* * * \#}$ & $13.2 \pm 1.6^{* * * \# \# \#}$ & $8.4 \pm 1.1^{* * *}$ \\
& 30 & $45.5 \pm 3.3^{* * \# \#}$ & $14.7 \pm 1.4^{* * \# \#}$ & $12.6 \pm 2.3^{\# \# \#}$ \\
Yunnan Baiyao & 20 & $50.2 \pm 3.9^{* * * \# \#}$ & $15.6 \pm 0.8^{* * \# \#}$ & $16.2 \pm 2.0^{* * \# \#}$ \\
$0.90 \% \mathrm{NaCl}$ & 0.5 & $33.3 \pm 3.8^{* * * * *}$ & $5.6 \pm 0.7^{* * * *}$ & $12.9 \pm 1.4^{* * *}$ \\
& & $59.7 \pm 5.4$ & $19.3 \pm 2.1$ & $16.7 \pm 3.6$ \\
\hline
\end{tabular}

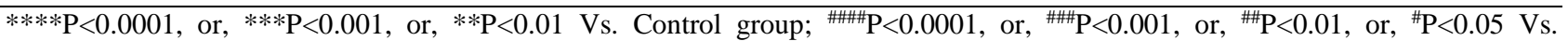
Yunnan Baiyao 


\section{Coagulation Activity}

Coagulation is a series of enzymatic reactions, activated by Pre correlation factors, ultimately produces thrombin and fibrin. APTT is a screening test to test whether the endogenous blood coagulation system is normal. PT is a screening test that reflects whether the exogenous coagulation pathway is normal. TT refers to the time required for blood clotting after thrombin is added to plasma. It is commonly used to test the function of blood coagulation, anticoagulation and fibrinolytic system (Jastrzebski et al., 2014). As shown in Table 3, the coagulation activity was positively correlated with the sample concentration. Moreover, compared with Yunnan Baiyao, APTT, PT and TT time of high concentration EOSAA were shortened by $28.83,42.86$ and $68.99 \%$, respectively. Since EOSAA affects APTT, PT and TT, it is indicated that it affects the coagulation function through the way of endogenous and exogenous coagulation or/and common. This is consistent with the application of $A$. argyle leaves to the treatment of menorrhagia, leakage, hemostasis and other blood syndromes (Dhanapal et al., 2016). Since the coagulation activity of the EOSAA was reported for the first time and the pharmacological study of the essential oil from A. Argyi was mainly conducted in animal experiments, the coagulation mechanism of the specific components remains to be further studied.

\section{Conclusion}

EOSAA was extracted by hydrodistillation and the extraction rate was $0.20 \%$. A total of 36 compounds were identified by GC-MS, accounting for $93.75 \%$ of the total coment, which its large amount of constituents is terpenoids such as eucalyptol, borneol, camphor and so on. The EOSAA has a certain inhibitory effect on Escherichia coli, Staphylococcus aureus and Bacillus pumilus. The time of APTT, PT and TT were shortened, indicating that EOSAA had a certain coagulation effect. Therefore, EOSAA is a kind of coagulant with antibacterial effect, which has potential application prospects in cosmetics and medicine. This research provides value for the further development and utilization of the stem of $A$. argyle.

\section{Nomenclature}

EOSAA: The essential oil from the stem of Artemisia argyle H. Lév.

EOLAA: The essential oil from the leaves of Artemisia argyle H. Lév.

A. argyle: Artemisia argyle H. Lév.

GC-MS: Gas Chromatography-Mass Spectrometer.

DMSO: Dimethyl sulfoxide.

APTT: Activated partial thromboplastin time.

TT: Thrombin time.
PT: $\quad$ Prothrombin time.

MIC: Minimum Inhibitory Concentration.

\section{Acknowledgement}

This investigation was supported by the Science and Technology Department of Jilin Province (Grant No. 20190304102YY).

\section{Author's Contributions}

Jiale Shan: The chemical composition, antibacterial and coagulation activity of the EOSAA were studied and analyzed in detail.

Hongli Zhou: Design experimental of this manuscript.

\section{Ethics}

This article is original and contains unpublished material. The corresponding author confirms that all of the other authors have read and approved the manuscript and no ethical issues involved.

\section{References}

Adams, J. D., Garcia, C., \& Garg, G. (2012). Mugwort (Artemisia vulgaris, Artemisia douglasiana, Artemisia argyi) in the treatment of menopause, premenstrual syndrome, dysmenorrhea and attention deficit hyperactivity disorder. Chinese Medicine, 3, 116-123. https://doi.org/10.4236/cm.2012.33019

Asadollahi, A., Khoobdel, M., Zahraei-Ramazani, A., Azarmi, S., \& Mosawi, S. H. (2019). Effectiveness of plant-based repellents against different Anopheles species: a systematic review. Malaria Journal, 18(1), 1-20. https://doi.org/10.1186/s12936-019-3064-8

Chzhu, O. P., Araviashvili, D. E., \& Danilova, I. G. (2020). Studying properties of prospective biologically active extracts from marine hydrobionts. Emerging Science Journal, 4(1), 37-43. https://doi.org/10.28991/esj-2020-01208

de Morais, S. R., Oliveira, T. L. S., de Oliveira, L. P., Tresvenzol, L. M. F., da Conceição, E. C., Rezende, M. H., ... \& de Paula, J. R. (2016). Essential oil composition, antimicrobial and pharmacological activities of Lippia sidoides Cham. (Verbenaceae) from Sao Goncalo do Abaete, Minas Gerais, Brazil. Pharmacognosy Magazine, 12(48), 262-270. https://doi.org/10.4103/0973-1296.192197

Dhanapal, A. C. T. N., Ming, T. W., Aung, H. P., \& Hao, S. J. (2016). Preliminary screening of Artemisia argyi for antioxidant potentials. International Journal of Pharmacognosy and Phytochemical Research, 8(2), 347-355. http://impactfactor.org/PDF/IJPPR/8/IJPPR,Vol8,Iss ue2,Article23.pdf 
Dore, C. M. P. G., Alves, M. G. D. C. F., Will, L. S. E. P., Costa, T. G., Sabry, D. A., ... \& Leite, E. L. (2013). A sulfated polysaccharide, fucans, isolated from brown algae Sargassum vulgare with anticoagulant, antithrombotic, antioxidant and anti-inflammatory effects. Carbohydrate Polymers, 91(1), 467-475. https://doi.org/10.1016/j.carbpol.2012.07.075

Guan, X., Ge, D., Li, S., Huang, K., Liu, J., \& Li, F. (2019). Chemical composition and antimicrobial activities of Artemisia argyi Lévl. et Vant essential oils extracted by simultaneous distillationextraction, subcritical extraction and hydrodistillation. Molecules, 24(3), 483. https://doi.org/10.3390/molecules24030483

Hu, H., Li, Q., Chen, S., Liu, Y., Gong, H., \& Jin, B. (2020). Preparation of the Essential Oil from Artemisia Argyi Grown in Qichun, China and its application in Antibacterial effection. In E3S Web of Conferences (Vol. 189, p. 02016). EDP Sciences. https://doi.org/10.1051/e3sconf/202018902016

Huang, H. C., Wang, H. F., Yih, K. H., Chang, L. Z., \& Chang, T. M. (2012). Dual bioactivities of essential oil extracted from the leaves of Artemisia argyi as an antimelanogenic versus antioxidant agent and chemical composition analysis by GC/MS. International Journal of Molecular Sciences, 13(11), 14679-14697. https://doi.org/10.3390/ijms131114679

Jastrzebski, P., Adamiak, Z., Pomianowski, A., Krystkiewicz, W., Holak, P., Sawicki, S., ... \& Gudzbeler, G. (2014). Response of the coagulation system after application of hemostatic dressings in an animal model. Polish Journal of Veterinary Sciences, 17, 725-727. https://doi.org/10.2478/pjvs-2014-0106

Jiang, Z., Guo, X., Zhang, K., Sekaran, G., Cao, B., Zhao, Q., ... \& Zhang, X. (2019). The essential oils and eucalyptol from Artemisia vulgaris L. prevent acetaminophen-induced liver injury by activating Nrf2-Keap1 and enhancing APAP clearance through non-toxic metabolic pathway. Frontiers in Pharmacology, 10, 782.

https://doi.org/10.3389/fphar.2019.00782

Junjie, X. U., Jinqing, L. U., \& Shengnan, G. U. O. (2016). Chemical Components and Their Antioxidant Activities in vitro of Volatile Oils from Leaves of Artemisia argyi: A Case Study of Qiai. Medicinal Plant, 7, 13-16.

https://www.proquest.com/openview/c98aac1eb49dc 3880456f3cf91149736/1?pq-

origsite $=$ gscholar $\& \mathrm{cbl}=1596361$

Lae, K. Z. W., Su, S. S., Win, N. N., Than, N. N., \& Ngwe, H. (2019). Isolation of Lasiodiplodin and Evaluation of some Biological Activities of the Stem Barks of Phyllanthus Albizzioides (Kurz) Hook. f. SciMedicine Journal, 1(4), 199-216. https://doi.org/10.28991/SciMedJ-2019-0104-5
Li, N., Mao, Y., \& Zhang, X. (2008). Separation and identification of volatile constituents in Artemisia argyi flowers by GC-MS with SPME and steam distillation. Journal of Chromatographic Science, 46(5), 401-405. https://doi.org/10.1093/chromsci/46.5.401

Martinichen-Herrero, J. C., Carbonero, E. R., Sassaki, G. L., Gorin, P. A. J., \& Iacomini, M. (2005). Anticoagulant and antithrombotic activities of a chemically sulfated galactoglucomannan obtained from the lichen Cladonia ibitipocae. International Journal of Biological Macromolecules, 35, 97-102. https://doi.org/10.1016/j.ijbiomac.2004.12.002

Padalia, R. C., Verma, R. S., Chauhan, A., Chanotiya, C. S., \& Thul, S. (2016). Phytochemical diversity in essential oil of Vitex negundo L. populations from India. Records of Natural Products, 10(4), 452-464. http://neeri.csircentral.net/616/

Pan, X. H., Wang, J. M., Wu, T. C., \& Sun, Y. F. (2012). Compound extraction and component analysis on volatile oil of Artemisia argyi. In Advanced Materials Research, 465, 255-261).

https://doi.org/10.4028/www.scientific.net/AMR.46 5.255

Popović, V., Petrović, S., Pavlović, M., Milenković, M., Couladis, M., Tzakou, O., ... \& Niketić, M. (2010). Essential oil from the underground parts of Laserpitium zernyi: potential source of $\alpha$-bisabolol and its antimicrobial activity. Natural Product Communications, 5(2), 307-310. https://doi.org/10.1177/1934578X1000500228

Rehman, N. U., Alam, T., Alhashemi, S. F. M., Weli, A. M., Al-Thani, G. S. S., Al-Omar, W. I., \& AlHarrasi, A. (2021). The GC-MS Analysis of the Essential Oil of Cleome austroarabica. Chemistry of Natural Compounds, 57(1), 174-176. https://doi.org/10.1007/s10600-021-03311-3

Smith-Palmer, A., Stewart, J., \& Fyfe, L. (2001). The potential application of plant essential oils as natural food preservatives in soft cheese. Food Microbiology, 18(4), 463-470. https://doi.org/10.1006/fmic.2001.0415

Sparkman, O. D. (2005). Identification of essential oil components by gas chromatography/quadrupole mass spectroscopy Robert P. Adams. Journal of the American Society for Mass Spectrometry, 16(11), 1902-1903. https://doi.org/10.1016/j.jasms.2005.07.008

Sun, Y., Chen, X., Liu, S., Yu, H., Li, R., Wang, X., ... \& Li, P. (2018). Preparation of low molecular weight Sargassum fusiforme polysaccharide and its anticoagulant activity. Journal of Oceanology and Limnology, 36(3), 882-891. https://doi.org/10.1007/s00343-018-7089-6 
Tan, R., \& Jia, Z. (1992). Eudesmanolides and other constituents from Artemisia argyi. Planta Medica, 58(04), 370-372. https://doi.org/10.1055/s-2006-961488

Toledo, A. G., de Souza, J. G. D. L., da Silva, J. P. B., Favreto, W. A. J., da Costa, W. F., \& da Silva Pinto, F. G. (2020). Chemical composition, antimicrobial and antioxidant activity of the essential oil of leaves of Eugenia involucrata DC. Bioscience Journal, 36(2), 568-577. https://doi.org/10.14393/BJ-v36n2a2020-48096

Wang, X., Zhang, Z., Yao, Z., Zhao, M., \& Qi, H. (2013). Sulfation, anticoagulant and antioxidant activities of polysaccharide from green algae Enteromorpha linza. International Journal of Biological Macromolecules, 58, 225-230. https://doi.org/10.1016/j.ijbiomac.2013.04.005

Xiang, F., Bai, J., Tan, X., Chen, T., Yang, W., \& He, F. (2018). Antimicrobial activities and mechanism of the essential oil from Artemisia argyi Levl. et Van. var. argyi cv. Qiai. Industrial Crops and Products, $125,582-587$. https://doi.org/10.1016/j.indcrop.2018.09.048

Yang, S. K., Yusoff, K., Ajat, M., Thomas, W., Abushelaibi, A., Akseer, R., ... \& Lai, K. S. (2019). Disruption of KPC-producing Klebsiella pneumoniae membrane via induction of oxidative stress by cinnamon bark (Cinnamomum verum J. Presl) essential oil. PloS One, 14(4), e0214326. https://doi.org/10.1371/journal.pone.0214326

Yu, F. R., Sun, L. L., Dai, Y. P., \& Zhou, Q. (2012). Optimization of Processing Technology for Artemisia argyi Carbonisatus with Vinegar [J]. Chinese Journal of Experimental Traditional Medical Formulae. https://en.cnki.com.cn/Article_en/CJFDTotalZSFX201214006.htm
Zacchino, S. A., Butassi, E., Cordisco, E., \& Svetaz, L. A. (2017). Hybrid combinations containing natural products and antimicrobial drugs that interfere with bacterial and fungal biofilms. Phytomedicine, 37, 14-26. https://doi.org/10.1016/j.phymed.2017.10.021

Zengin, H., \& Baysal, A. H. (2014). Antibacterial and antioxidant activity of essential oil terpenes against pathogenic and spoilage-forming bacteria and cell structure-activity relationships evaluated by SEM microscopy. Molecules, 19(11), 17773-17798. https://doi.org/10.3390/molecules 191117773

Zhang, F., Wang, F., Xiao, L., \& Sun, G. (2014). Inhibitory activity of ethanol extract from Artemisia argyi on a clinical isolate of Staphylococcus aureus. Chinese Medicine, 5(04), 244. https://doi.org/10.4236/cm.2014.54029

Zhang, L. B., Lv, J. L., Chen, H. L., Yan, X. Q., \& Duan, J. A. (2013). Chemical constituents from Artemisia argyi and their chemotaxonomic significance. Biochemical Systematics and Ecology, 50, 455-458. https://doi.org/10.1016/j.bse.2013.06.010

Zheng, L., Ben, L., Cui, Z., Fu, Q., Wang, L., Qi, B., \& Zhang, Y. (2019). The Phytol-rich Essential Oil from Fresh Medicago hispida Exerts Significant Inhibitory Activity against Escherichia coli. American Journal of Biochemistry and Biotechnology, 15. 270-274. https://doi.org/10.3844/ajbbsp.2019.270.274

Zheng, X., Deng, C., Song, G., \& Hu, Y. (2004). Comparison of essential oil composition of Artemisia argyi leaves at different collection times by headspace solid-phase microextraction and gas chromatography-mass spectrometry. Chromatographia, 59(11), 729-732. https://doi.org/10.1365/s10337-004-0306-9 